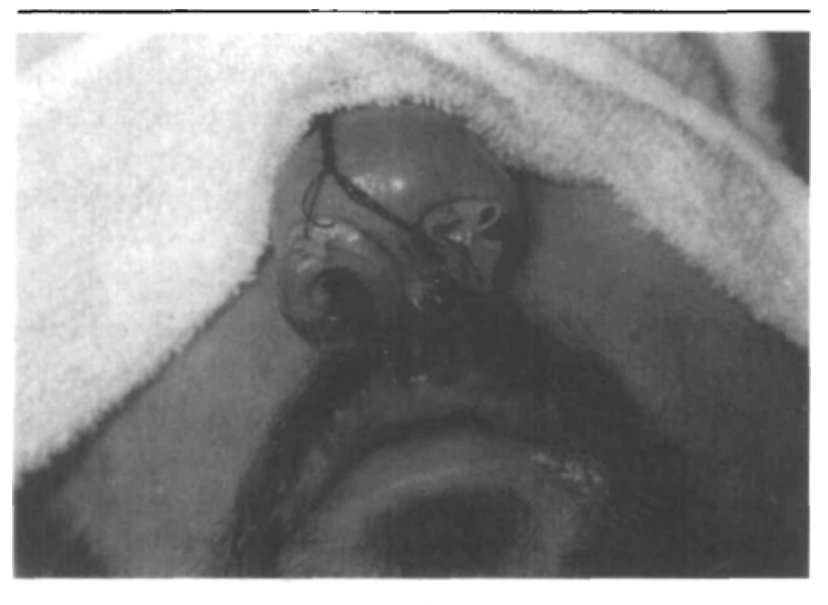

FIGURE Modification of nasal packing to improve patient comforc after transsphenoidal surgery.

ly is one of the major complaints patients have in the postoperative period. It creates patient anxiety and discomfort related to the subjective feeling of not getting enough air.

Recently we asked the surgeons to insert a properly sized nasal trumpet in one nostril prior to packing the nose, with the gauze rolls packed around the nasal trumpet, as illustrated in the Figure. The length of the trumpet is shortened such that it does not extend too far into the nasopharynx. We have used this modified nasal pack in over 30 patients undergoing transsphenoidal surgery and have not had any problems since the patient discomfort related to the inability of nasal breathing. Although respiration is probably insufficient through one nasal trumpet, the patient's subjective feeling is improved by allowing some air passage through the nose.

Jan Sendker MD

Nevin S. Kreisler MD

Burkhard F. Spiekermann MD

Charlottesville, VA, USA

\section{Combined spinal and epidural anes- thesia for major abdominal surgery in infants}

To the Editor:

I was interested to read of the 'new' combined spinalepidural (CSE) anesthesia in awake babies. ${ }^{1}$ The technique is not new: we described it in $1994 .{ }^{2}$ We preferred this to our previous technique of epidural anesthesia through caudal catheters ${ }^{3}$ because it produced rapid onset of a dense motor and sensory block. This extended the duration of block for prolonged surgery with an advantage over often limited and sometimes short duration of spinal anesthesia alone.

Williams and colleagues have considerable experience of regional anesthesia in awake babies and it would have been interesting to set their report within the context of experience in more than 800 babies. What are the indications for CSE anesthesia and what factors are important for success? We found the technique was less successful in full-term than ex-premature babies. What determined the choice of midazolam or propofol instead of inhalational agents in babies requiring sedation? The authors describe the technique in 19 babies: did they make unreported attempts in others?

Williams reported subarachnoid placement of the caudal catheter $(24 \mathrm{~g})$ in one of 19 babies and a subsequent total spinal. Van Niekerk reported two misplaced $23 \mathrm{~g}$ caudal catheters in 20 pre-term babies (one intravascular, one subarachnoid); ${ }^{4}$ blood or CSF were not aspirated. These potentially serious complications with small diameter catheters may be relatively common. Since this report and the audit by Wilson ${ }^{5} \mathrm{I}$ have used a larger catheter (external diameter $0.9 \mathrm{~mm}$ ) with 3 lateral eyes in babies $>3.5 \mathrm{~kg}$ in the belief aspiration through misplaced catheters is more likely.

Jane $M$. Peutrell MB BS FRCP FRCA

Glasgow, United Kingdom

\section{REFERENCES}

1 Williams RK, McBride WJ, Abajian JC. Combined spinal and epidural anaesthesia for major abdominal surgery in infants. Can J Anaesth 1997; 44: 511-4.

2 Peutrell JM, Hughes DG. Combined spinal and epidural anesthesia for inguinal hernia repair in babies. Pacdiatric Anacsthesia 1994; 4: 221-7.

3 Peutrell JM, Hughes DG. Epidural anaesthesia through caudal catheters for inguinal herniotomies in awake expremature babies. Anaesthesia 1993; 47: 128-31.

4 Van Niekerk J, Bax-Vermeire BMJ, Geurts JWH, Kramer PPG. Epidurography in premature infants. Anaesthesia 1990; 45: 722-5.

5 Wilson PTJ, Lloyd-Thomas AR. An audit of cxtradural infusion analgesia in children using bupivacaine and diamorphine. Anaesthesia 1993; 48: 718-23.

\section{REPLY:}

We gratefully acknowledge Dr. Peutrell's important contribution to the practice of regional anesthesia in infants. Paediatric Anaesthesia was not cited in most 
medical databases when her work was published and several computerized searches do not mention Dr. Peutrell's work. Our work concerning the technique bas been discussed widely without any of our colleagues mentioning Dr. Peutrell's work. We believe Dr. Peutrell's work is important and we shall cite her paper in a review article on infant spinal anesthesia we are preparing for publication 1999. 'Little of this is truly "new"... Bainbridge, and later on Gray, reported on spinal anesthesia in infants around the turn of the century and by 1933, Junkin described the use of spinal anesthesia for thoracic surgical procedures in children. ${ }^{2-4}$

Dr. Peutrell's report concerned the use of this technique to perform inguinal bernia repair. In our institution, we are able to perform inguinal hernia repair in children under a single shot technique with hyperbaric tetracaine and epinepbrine. The main point of our paper was to stress that major abdominal surgery in infants can be carried out without general anesthesia, endotracheal intubation and the potential need for postoperative ventilation. We use this technique for most surgical procedures below the level of the diaphragm in both premature and term infants. Our collective experience with infant spinal anesthesia now totals in excess of 1,000 cases and we have utilized the combined technique for more than 30 patients. The presence of a catheter also provides for post-op pain control.

Robert K. Williams MD

J. Christian Abajian MD

Vermont, USA

\section{REFERENCES}

1 Williams $R$, Abajian JC. Infant spinal anesthesia. In: Busoni P (Ed.). Techniques in Regional Anesthesia and Pain Management, 1999: (In publication).

2 Bainbridge WS. Report of 12 operations on infants and young children under spinal anesthesia. Arch Pediatr 1901; 18: 510-20.

3 Gray HT. A study of spinal anesthesia in children and infants. Lancet 1901; 3: 913-7.

4 Junkin C. Spinal anesthesia in children. Can Med Assoc J 1933; 28: 51-3. 